\title{
The AR/NCOA1 axis regulates prostate cancer migration by involvement of PRKD1
}

\author{
Birgit Luef1, Florian Handle1, Gvantsa Kharaishvili2, Martina Hager³, \\ Johannes Rainer ${ }^{4}$, Günter Janetschek5 ${ }^{5}$ Stephan Hruby5, Christine Englberger5, \\ Jan Bouchal2, Frédéric R Santer1,* and Zoran Culigi,*
}

1Division of Experimental Urology, Department of Urology, Medical University of Innsbruck, Innsbruck, Austria 2Department of Clinical and Molecular Pathology and Institute of Molecular and Translational Medicine, Faculty of Medicine and Dentistry, Palacky University, Olomouc, Czech Republic 3Department of Pathology, Paracelsus Medical University, Salzburg, Austria ${ }^{4}$ Division of Molecular Pathophysiology, Biocenter, Medical University of Innsbruck, Innsbruck, Austria ${ }^{5}$ Department of Urology, Paracelsus Medical University, Salzburg, Austria *(F R Santer and Z Culig share senior authorship)

Correspondence should be addressed to Z Culig or F R Santer Email

zoran.culig@i-med.ac.at or frederic.santer@i-med.ac.at

\begin{abstract}
Due to the urgent need for new prostate cancer ( $\mathrm{PCa}$ ) therapies, the role of androgen receptor (AR)-interacting proteins should be investigated. In this study we aimed to address whether the AR coactivator nuclear receptor coactivator 1 (NCOA1) is involved in PCa progression. Therefore, we tested the effect of long-term NCOA1 knockdown on processes relevant to metastasis formation. $\left[{ }^{3} \mathrm{H}\right]$-thymidine incorporation assays revealed a reduced proliferation rate in AR-positive MDA PCa $2 \mathrm{~b}$ and LNCaP cells upon knockdown of NCOA1, whereas AR-negative PC3 cells were not affected. Furthermore, Boyden chamber assays showed a strong decrease in migration and invasion upon NCOA1 knockdown, independently of the cell line's AR status. In order to understand the mechanistic reasons for these changes, transcriptome analysis using CDNA microarrays was performed. Protein kinase D1 (PRKD1) was found to be prominently up-regulated by NCOA1 knockdown in MDA PCa 2b, but not in PC3 cells. Inhibition of PRKD1 reverted the reduced migratory potential caused by NCOA1 knockdown. Furthermore, PRKD1 was negatively regulated by AR. Immunohistochemical staining of PCa patient samples revealed a strong increase in NCOA1 expression in primary tumors compared with normal prostate tissue, while no final conclusion could be drawn for PRKD1 expression in tumor specimens. Thus, our findings directly associate the AR/NCOA1 complex with $P R K D 1$ regulation and cellular migration and support the concept of therapeutic inhibition of NCOA1 in PCa.
\end{abstract}

\section{Introduction}

Localized prostate cancer (PCa) can successfully be treated by prostatectomy and radiotherapy so that the cure is achievable. Androgen-deprivation therapy (ADT) remains the gold standard treatment for patients with locally advanced and metastatic disease. Although the treatment is initially successful, most patients progress within 2-3 years to castration-resistant PCa (Karantanos et al. 2013). Mutation or overexpression of the androgen 
receptor (AR) as well as $\mathrm{AR}$ coregulator up-regulation have been implicated in reactivation of the AR signaling pathway during ADT (Culig \& Santer 2014). AR mutations in the ligand-binding domain (LBD) and occurrence of truncated AR, which lack the LBD and are constitutively active (Karantanos et al. 2013), compromise efficacy of the antiandrogens, as they were designed to target the LBD of the AR. Prolonged treatment of PCa cells with several antiandrogens may result in increased frequency of AR point mutations. Ligand-independent activation of the AR by interleukin-6 and ErbB2 may contribute to in vivo progression of PCa (Craft et al. 1999, Malinowska et al. 2009). Thus, AR still remains the main target in PCa treatment in this progressed stage and there is a vigorous need for the development of new strategies to inhibit the AR via a different approach such as targeting AR interacting proteins, e.g. coactivators (Nakka et al. 2013).

Coactivator proteins are recruited to a ligandbound receptor and thereby enhance its transcriptional activity (Powell et al. 2004). So far, there are 300 known coactivators for nuclear receptors, including nuclear receptor coactivator 1 (NCOA1/SRC1), which is a member of the p160 nuclear receptor coactivator family. This protein family also contains two additional proteins NCOA2 (GRIP-1, SRC-2) and NCOA3 (AIB1, SRC-3). NCOA1 acts as a scaffold protein that houses a central nuclear receptor-interacting domain and two activation domains, which are located at the carboxy-terminus and flank a glutamine-rich region. This glutamine-rich region interacts with the amino-terminal part of the AR (Powell et al. 2004).

NCOA1 has already been shown to interact not only with nuclear receptors but also with nonsteroidal transcription factors, such as polyoma enhancer activator 3 (PEA3) (Qin et al. 2009) and Ets-2 (McBryan et al. 2012). Moreover, NCOA1 has an important role in promoting metastasis, which was shown in genetically engineered breast cancer mouse models by Wang and coworkers (2009).

In this study, we aimed to clarify the influence of NCOA1 in PCa metastasis formation. Using an RNAi approach to generate stable NCOA1 knockdown cell lines, we investigated the effect on migration and invasion as well as on differentially regulated genes, with particular interest on the effects in a castration-resistant cell line model. Migration and invasion assays revealed that NCOA1 is implicated in this process independently of the AR status of the cell lines. In addition, we can show that PRKD1 is a direct target of the AR/NCOA1 complex and negatively regulates migration. Our data suggest that specifically targeting NCOA1 could restore PRKD1 expression and reduce the migratory capability of tumor cells.

\section{Materials and methods}

\section{Cell lines and reagents}

The human PCa cell lines LNCaP FGC, VCaP, MDA PCa 2b, CWR22Rv1, PC3 and Du145 were obtained from the American Type Culture Collection (ATCC, Rockville, MD, USA). All cell lines were grown and subcultured according to the recommendations of ATCC unless otherwise stated. LNCaP sublines LNCaP-IL6+ (Hobisch et al. 2001) and LNCaP-abl (Culig et al. 1999) were previously described. DuCaP cells were a kind gift from Prof. J A Schalken (Nijmegen, The Netherlands) and were grown in RPMI 1640 containing 10\% (v/v) FCS (PAA Laboratories, Pasching, Austria), antibiotics (100 units/mL penicillin; 100 units/mL streptomycin) (Lonza) and $2 \mathrm{mM}$ GlutaMAX (Life Technologies, Thermo Fisher). LAPC4 cells, kindly provided by Dr A Cato (Institute of Toxicology and Genetics, Karlsruhe, Germany), were cultured as mentioned previously (Santer et al. 2011). HEK 293FT cells were purchased from Life Technologies and grown according to the manufacturer's protocol. Cell line authenticity was confirmed by short tandem repeat analysis in 2015 (Parson et al. 2005). For experiments, all cell lines were seeded at subconfluent density in six-well plates. LNCaP and MDA PCa $2 \mathrm{~b}$ cells were seeded onto poly-D-lysine hydrobromide (Sigma-Aldrich) precoated plates. Methyltrienolone (R1881) and enzalutamide (MDV3100) were obtained from Organon (Oss, The Netherlands) and Eurasia Chemicals (Mumbai, India), respectively, and dissolved in ethanol or DMSO, at appropriate stock solutions.

\section{Generation of stable knockdown models}

Cell lines with a stable knockdown of NCOA1 were generated by lentiviral-based transduction of shRNA vectors. In detail, two different sequence-verified shRNA lentiviral pLKO.1-puro plasmids targeting NCOA1 (shNCOA1\#1; Clone ID: NM_003743.x-1939s1c1 and shNCOA1\#2; Clone ID: NM_003743.x-4630s1c1) as well as a nonmammalian shRNA control plasmid (shCTRL; SHC002; pLKO.1-puro) were purchased from the RNAi consortium (Sigma-Aldrich). To produce lentiviral particles, HEK293FT cells were seeded at a density of $0.8 \times 10^{6}$ in six-well plates and cotransfected with $5 \mu \mathrm{g}$ lentiviral

Published by Bioscientifica Ltd 
vector, $3 \mu \mathrm{g}$ pVSV-G and $3 \mu \mathrm{g}$ psPAX2 (both vectors were kindly provided by Prof. S Geley, Division of Molecular Pathophysiology, Medical University of Innsbruck) using Lipofectamine 2000 reagent (Life Technologies) on the next day. Virus containing supernatants were collected 48 and $72 \mathrm{~h}$ after transfection and filtered through a $0.45 \mu \mathrm{m}$ filter. Target cells were infected with the virus containing supernatant in presence of $4 \mu \mathrm{g} / \mathrm{mL}$ Polybrene (SigmaAldrich) and selected with puromycin $(1-2.5 \mu \mathrm{g} / \mathrm{mL})$ (Sigma-Aldrich).

Cell lines with a stable knockdown of PRKD1 were generated with Invitrogen's BLOCK-iT system, using a blasticidin selection marker to allow selection in puromycin-resistant cells. Briefly, miR Select oligos (Hmi413641: miR-A; Hmi413642: miR-B) were purchased from Life Technologies and cloned into pcDNA 6.2-GW/EmGFP-miR expression vector. Next, the expression cassettes were shuttled via MultiSite Gateway recombination reaction into the pLenti6.4/R4R2/V5-DEST in combination with the pENTR5'/EF1 $\alpha$ p vector. Cells were transduced by a lentiviral approach as described above and selected by $5 \mu \mathrm{g} / \mathrm{mL}$ blasticidin. All cell lines selected for stable integration of vectors were used as polyclonal mixture in subsequent experiments.

\section{RNA isolation and quantitative real-time PCR}

Quantitative real-time PCR was performed as described previously (Erb et al. 2013). TaqMan gene expression assays for NCOA1 (Hs00186661_m1), PRKD1 (Hs00177037_m1), PLA2G7 (Hs00965837_m1), EIF5A2 (Hs00702673_s1), HMBS (Hs00609297_m1), FKBP5 (Hs01561006_m1), ADAMTS9 (Hs00965746_m1), FGF12 (Hs00912823_m1), CSF1 (Hs00174164_m1), MDK (Hs00171064_m1) and ITGA6 (Hs01041011_m1) were purchased from Life Technologies. Custom Taqman gene expression assays were synthesized by GenXpress: PSA (fwd, 5'-GTCTGCGGCGGTGTTCTG-3'; rev, 5'-TGCCGACCC AGCAAGATC-3'; probe, 5'-FAM-CACAGCTGCCCACTGC ATCAGGA-TAMRA-3'). TBP (fwd, 5'-CACGAACCACGGC ACTGATT-3'; rev, 5'-TTTTCTTGCTGCCAGTCTGGAC-3'; probe, 5'-FAM-TCTTCACTCTTGGCTCCTGTGCACA-TAM RA-3') and HPRT1 (fwd 5'-GCTTTCCTTGGTCAGGC AGTA-3'; rev 5'-GTCTGGCTTATATCCAACACTTCGT-3'; probe, 5'-FAM-TCAAGGTCGCAAGCTTGCTGGTGAAAA GGA-TAMRA-3'). HPRT1, TBP and HMBS were used as endogenous controls as stated in the figure legends. ABI Sequence Detection Software was used to automatically determine the $\mathrm{Ct}$ values and gene expression was calculated using the $\Delta \Delta \mathrm{Ct}$ method.

\section{Prostate-specific antigen (PSA) measurements}

Cells were plated in six-well plates in normal growth medium. Next day, medium was changed and cells were grown for additional $48 \mathrm{~h}$. The supernatant was harvested and the secreted PSA was measured with an immunoassay (Roche) on a cobas 8000 modular analyzer (Hitachi). Secreted PSA was normalized to total protein amount.

\section{Western blot analysis}

Cell lysis was done with RIPA Buffer (50 mM Tris- $\mathrm{HCl}(\mathrm{pH}$ 7.3); $150 \mathrm{mM} \mathrm{NaCl}, 0.5 \%$ Na-Deoxycholat, $1 \% \mathrm{NP}-40$ ) and $50 \mathrm{\mu g}$ total protein was loaded onto an SDS-PAGE (NuPAGE Novex $4-12 \%$ Bis-Tris Gels). Proteins were transferred onto nitrocellulose membranes with $0.45 \mu \mathrm{m}$ pore size for $2 \mathrm{~h}$ at $30 \mathrm{~V}$ and $4^{\circ} \mathrm{C}$ with subsequent blocking in appropriate blocking buffers according to the manufacturer's protocol. The following primary antibodies were used: anti-NCOA1 (1:500, 128E7, Cell Signaling Technology), anti-GAPDH (1:50,000, MAB374, Millipore), anti-PRKD1 (1:200, D-20, Santa Cruz Biotechnology), anti-AR (1:500, N-20, Santa Cruz Biotechnology), anti-PSA (1:1000, D11E1, Cell Signaling Technology) and anti-FKBP5 (1:1000, BethylLaboratories, Montgomery, TX, USA).

\section{Proliferation assays}

$\left[{ }^{3} \mathrm{H}\right]$-thymidine incorporation assay was carried out as described previously (Hoefer et al. 2012). For determination of population doublings, a defined number of cells were seeded in T25 flask. After 3-4 days, cells were counted and population doublings (PDL) were determined with the following formula: $\mathrm{PDL}=3.32^{*}(\log 10(\mathrm{Xe})-\log 10(\mathrm{Xb}))+\mathrm{S}$, where $\mathrm{Xe}=$ cell number at the end of the incubation time, $\mathrm{Xb}=$ cell number at the beginning of the incubation time and $\mathrm{S}=$ starting PDL. Linear regression was used to fit the lines on data points.

\section{Cell migration and invasion assay}

Migration assays were performed with Boyden chambers (HTS FluoroBlok Cell Culture Inserts, $8 \mu \mathrm{m}$ pore size, Becton Dickinson) as described previously (Pasqualini et al. 2015) with the following modifications: PC3 and MDA PCa $2 b$ cells were seeded at a density of $2.5 \times 10^{4}$ and $7.5 \times 10^{4}$ cells, respectively. Equal numbers of cells were seeded in Boyden chambers with FluoroBlok cell culture inserts in duplicates. For invasion, inserts were coated with $30 \mu \mathrm{L}$ of a 1:3 dilution of matrigel (BD Matrigel Matrix).

Published by Bioscientifica Ltd 
A serum gradient of $1 \%$ vs $10 \%$ (for migration experiments) and $1 \%$ vs $30 \%$ (for invasion experiments) in the upper vs the lower membrane-separated chambers was used as chemoattractant. After $48 \mathrm{~h}$ (for migration experiments) or $72 \mathrm{~h}$ (for invasion experiments), cells were stained with Calcein-AM (Sigma-Aldrich; 1:10,000) and fluorescence images of the lower FluoroBlok membrane were taken using an Olympus IX70 microscope with a $4 \times$ objective. Determination of the number of migrated or invaded cells was performed using ImageJ software and normalized to the number of cells in a companion plate without the insert to correct for differences in proliferation.

\section{Affymetrix gene expression microarray}

Cells were seeded at a density of $4.0 \times 10^{5}$ in six-well plates and harvested after $48 \mathrm{~h}$, when cells reached $90 \%$ confluency, in $350 \mu \mathrm{L}$ RLT buffer from Qiagen's RNeasy Mini Kit for mRNA extraction with an on-column DNase digestion step. Subsequently, a GeneChip Human Gene 1.0 ST array (Affymetrix) was hybridized. Generation of the gene expression data set consisting of three biological replicates for each condition and preprocessing of the data set was performed as described previously (Bindreither et al. 2014). Differential expression analysis was performed using the moderated $t$-test (Smyth 2004) and the resulting p-values adjusted for multiple testing using the method from Benjamini and Hochberg $\left(\mathrm{p}_{\mathrm{BH}}\right)$ (Benjamini \& Hochberg 1995). Genes more than two-fold differentially expressed $(|\mathrm{M}|>1)$ at a $5 \%$ false discovery rate (adjusted $P$-value $<0.05$ ) were considered significantly differentially expressed. Raw and preprocessed gene expression data have been deposited at the Gene Expression Omnibus (GEO), accession number: GSE75531.

\section{Analysis of AR ChIP-Seq data}

Publicly available ChIP-Seq data from GEO database (GSE70679, GSE62442 and GSE65478) were analyzed for PRKD1 using the USCS browser. Bedtools was used to perform detailed analysis by calculating the coverage of aligned reads on $50 \mathrm{bp}$ windows. ARE motifs in the AR ChIP-Seq peaks were predicted using the JASPAR 2016 server with the AR-binding matrix model MA0007.2 using a relative profile score threshold of 85\% (Mathelier et al. 2015).
A

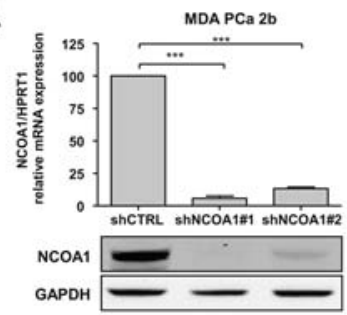

B

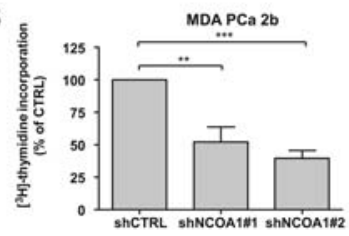

C

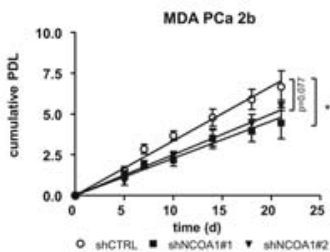

D

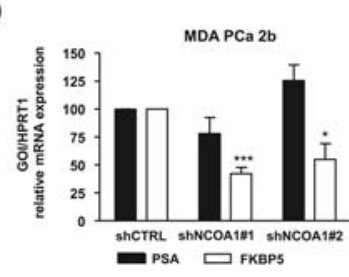

http://erc.endocrinology-journals.org DOI: $10.1530 /$ ERC-16-0160
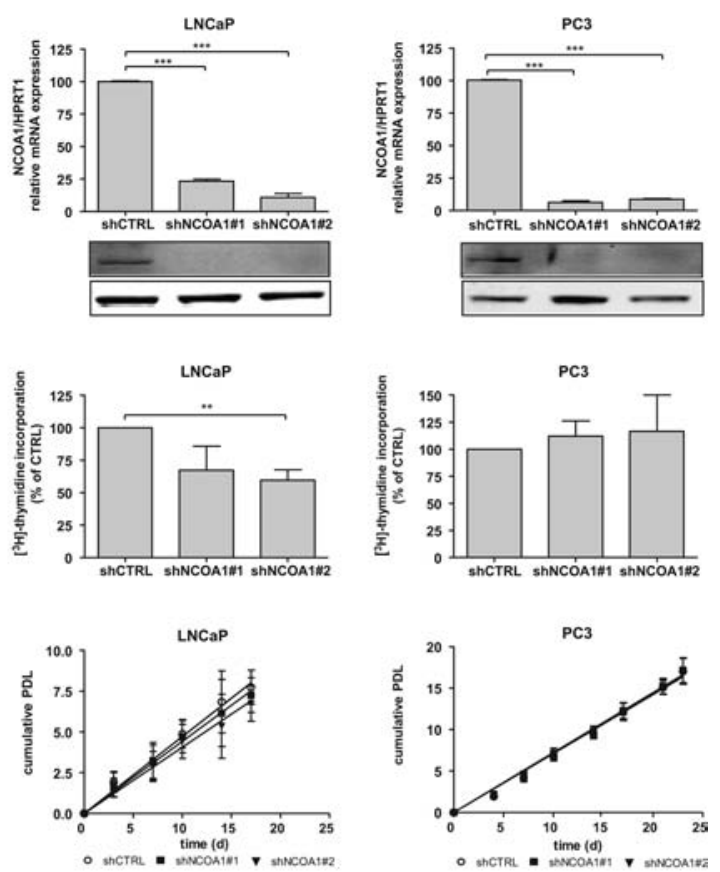

E
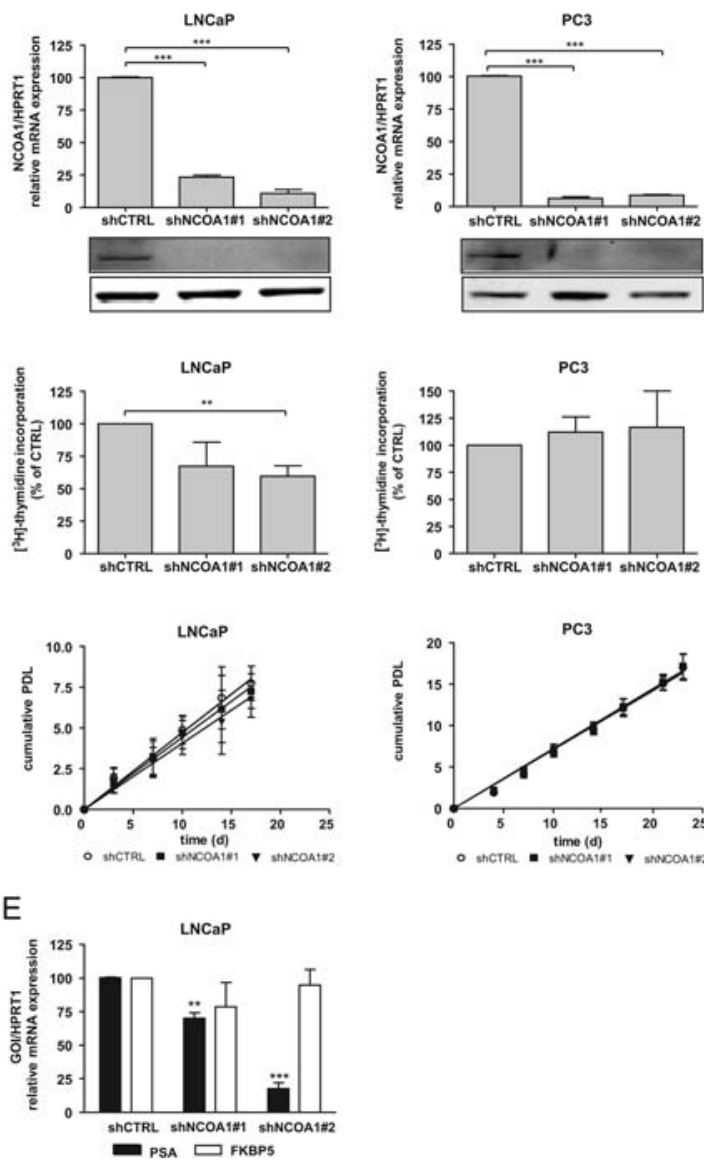

(2016 Society for Endocrinology Printed in Great Britain
Figure 1

NCOA1 knockdown differentially affects proliferation and AR transcriptional activity. (A) Establishment of stable NCOA1 knockdown cell lines. MDA PCa 2b, LNCaP and PC3 cells were stably transfected with either shRNA against NCOA1 (shNCOA1\#1 or shNCOA1\#2) or with a nonmammalian shRNA (shCTRL) sequence, respectively. Knockdown efficiency of NCOA1 was confirmed by means of qRT-PCR and Western blot experiments, respectively. Values indicated are mean \pm S.E.M. $(* * * P<0.001$; $t$-test, $n=3$ ). One representative Western blot out of three independent experiments is shown.

(B) Proliferation of NCOA1-depleted MDA PCa 2b, LNCaP and PC3 was assessed by $\left[{ }^{3} \mathrm{H}\right]$-thymidine incorporation assays. Incorporated $\left[{ }^{3} \mathrm{H}\right]$-thymidine was quantified and normalized to shCTRL expressing cell lines. The $\left[{ }^{3} \mathrm{H}\right]$-thymidine incorporation of ShCTRL cell lines was set to $100 \%$. Data show mean \pm S.E.M., $n=3$. (**P<0.01;***P<0.001, $t$-test).

(C) Cumulative population doubling levels (PDL) of various cell lines with stable integrated short-hairpin constructs were determined by cell counting upon each passage. Values are given as mean \pm S.E.M.; $n=3$. ( ${ }^{*} P<0.05$, Mann-Whitney $U$ test). ( $D$ and $E$ ) Transcriptional activity of the AR was assessed in NCOA1-depleted MDA PCa 2b (D) and LNCaP (E) cells by PSA and FKBP5 expression levels by means of qRT-PCR. Values indicated are mean \pm S.E.M. $\left({ }^{\star} P<0.05 ;{ }^{*} P<0.01\right.$; $* * * P<0.001 ;$ t-test, $n=3$ ). 


\section{Immunohistochemistry}

The use of archived samples derived from radical prostatectomy was approved by the Ethics Committee of the University Hospital and Medical Faculty of Palacky University in Olomouc and by the Ethics Committee of the Province of Salzburg, respectively. The staining of patients' samples was performed on a Discovery-XT staining device (Ventana, Tucson, AZ, USA). The histoscore (H-score) was used to semiquantitatively assess the staining considering percentage of positive cells (0-100\%) multiplied by staining intensity (0-3), which results in a final $\mathrm{H}$-score between 0 and 300 (Slabáková et al. 2015). The nuclear NCOA1 and the cytoplasmic PRKD1 staining in luminal cells were considered for analysis. For antibody validation, the staining in appropriate control cell lines was assessed. The following antibodies were used: anti-NCOA1 (128E7, 1:100, Cell Signaling Technology), anti-AR (clone AR441, 1:25, Dako), anti-PRKD1 (sc-935, D-20, 1:200, Santa Cruz Biotechnology) and anti-PRKD1_hpa (HPA029834, 1:200, Sigma-Aldrich). Antigen retrieval was done with Cell Conditioning Solution 1 (CC1 from Roche) for NCOA1, AR and PRKD1 (Santa Cruz) and pH9.0 antigen retrieval $(10 \mathrm{mM}$ Tris/Cl pH 9.0, 1mM EDTA, 0.05\% Tween-20) for PRKD1_hpa (Sigma-Aldrich). All stainings were performed in a single machine run and evaluated by experienced pathologists in Olomouc (GK) and Salzburg (MH), respectively.

\section{Statistical analysis}

Statistical analysis was performed using GraphPad Prism 4 and IBM SPSS Statistics 22 (IBM), respectively. Differences between the control and treatment groups were calculated using Mann-Whitney $U$ test, one-way ANOVA and Student's t-test, respectively, as described in the figure legends. $P$-values $<0.05$ were considered significant and encoded as follows: ${ }^{*} P<0.05$; ${ }^{* *} P<0.01 ;{ }^{* * *} P<0.001$.

\section{Results}

\section{NCOA1 down-regulation reduces proliferation and AR transcriptional activity in human prostate cancer cells}

NCOA1 mRNA and protein are expressed ubiquitously in all tested PCa cell lines at different levels. mRNA and protein levels within the same cell line did not necessarily correlate, showing that NCOA1 protein is prone to translational and/or post-translational regulation of expression (Supplementary Fig. 1A and B, see section on supplementary data given at the end of this article). To study the effect of NCOA1 depletion in AR-positive versus AR-negative cells, we generated stable NCOA1 knockdown cell lines by lentiviral transduction of two shRNAs in MDA PCa 2b, LNCaP and PC3 cells (Fig. 1A).
A
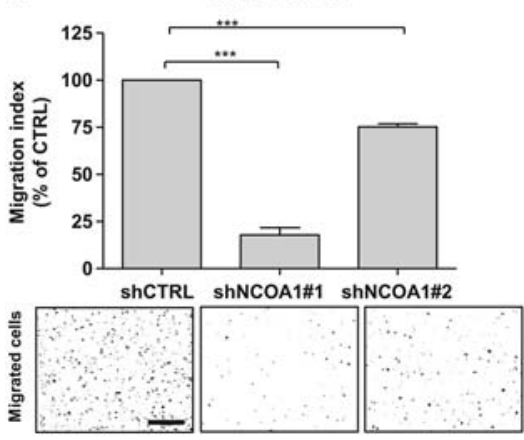

B

B MDA PCa 2b

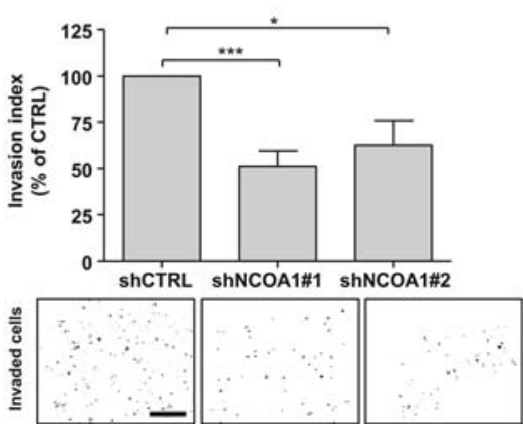

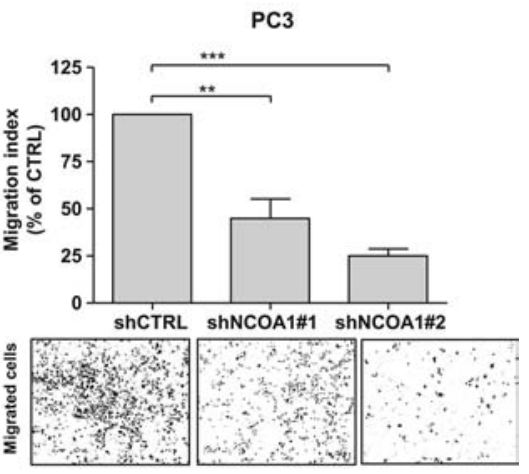

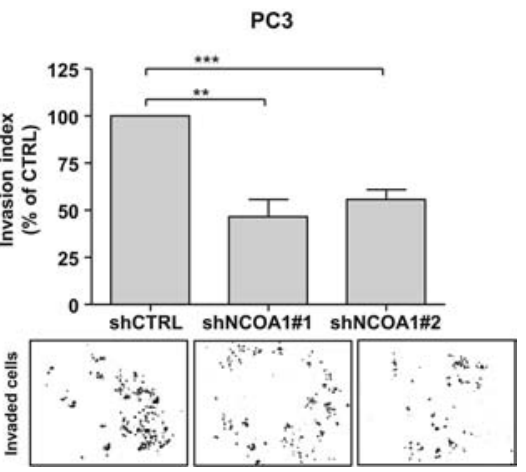

Figure 2

NCOA1 is implicated in prostate tumor cell migration and invasion. (A) Boyden chamber assays were performed with PC3 and MDA PCa $2 \mathrm{~b}$ cells. Migrated cells were determined using ImageJ and normalized to the cell number in a parallel well without the FluoroBlok cell culture insert to account for differences in proliferation through NCOA1 knockdown. Data show mean \pm s.E.M., $n=3 .(* * P<0.01 ; * * * P<0.001$, $t$-test). Scale bar: $500 \mu \mathrm{m}$ (B) As in (A), with additional coating of FluoroBlok cell culture inserts with a 1:3 dilution of matrigel and staining after $72 \mathrm{~h}$. Data represent mean \pm S.E.M., $n>4(* P<0.05 ; * * P<0.01 ; * * * P<0.001, t$-test $)$. Scale bar: $500 \mu \mathrm{m}$. 
To test the influence of NCOA1 down-regulation on cellular proliferation, we performed $\left[{ }^{3} \mathrm{H}\right]$-thymidine incorporation assays with MDA PCa 2b, LNCaP and PC3 cells. As shown in Fig. 1B, knockdown of NCOA1 markedly reduced the proliferation rate of MDA PCa $2 \mathrm{~b}$ cells by $50-60 \%$ and that of LNCaP cells, although to a lesser extent. In contrast, proliferation of PC3 cells was not affected by NCOA1 depletion. This finding could be confirmed using population doubling, which revealed a significantly reduced proliferation of MDA PCa $2 b$ shNCOA1\#2 compared with shCTRL. This trend could also be observed in MDA PCa 2b shNCOA1\#1 and both LNCaP knockdown cell lines. Concordant to the $\left[{ }^{3} \mathrm{H}\right]$-thymidine, PC3 cells were again not affected by NCOA1 knockdown (Fig. 1C).

Next, we investigated whether NCOA1 depletion affects AR transcriptional activity and assessed the expression of two AR downstream targets PSA and FKBP5 by qRT-PCR and Western blotting. While there was no change in PSA mRNA expression upon NCOA1 knockdown in MDA PCa $2 \mathrm{~b}$ cells, we could detect a significant decrease in FKBP5 mRNA expression (Fig. 1D). Surprisingly, intracellular PSA protein levels were increased in NCOA1-depleted MDA PCa 2b cells
(Supplementary Fig. 2A) but did not result in changed PSA secretion (Supplementary Fig. 2C). FKBP5 is expressed at a low level in this cell line model (Supplementary Fig. 2A). In contrast, in NCOA1-depleted LNCaP cells, PSA mRNA and protein expression were reduced, as well as secreted PSA (Supplementary Fig. 2D). FKBP5 levels were not altered on mRNA or on protein level (Fig. 1E and Supplementary Fig. 2B). In summary, this shows that the AR coactivator NCOA1 can influence AR target gene expression, but displays a high variability, depending on the cell line.

\section{NCOA1 is involved in prostate cancer cell migration and invasion independently of the AR status}

To test whether NCOA1 may be implicated in the process of metastasis formation in PCa, we performed Boyden chamber assays to investigate the migratory capacity in response to stable NCOA1 knockdown. Due to the low migratory capability of LNCaP cells, this experiment was performed only in MDA PCa $2 b$ and PC3 cells. We found that in the absence of NCOA1, migration was significantly diminished in MDA PCa $2 \mathrm{~b}$ cell lines,
A

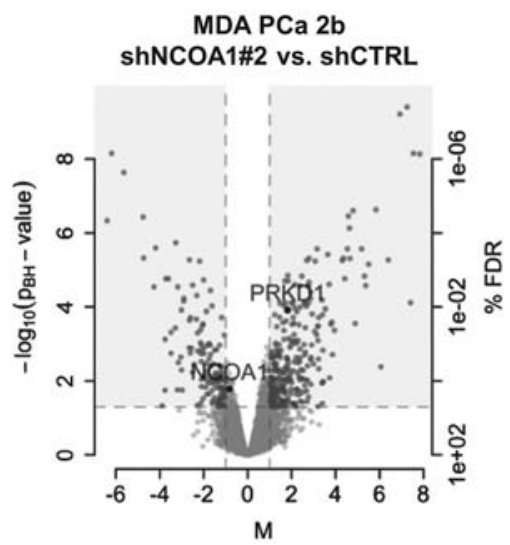

B

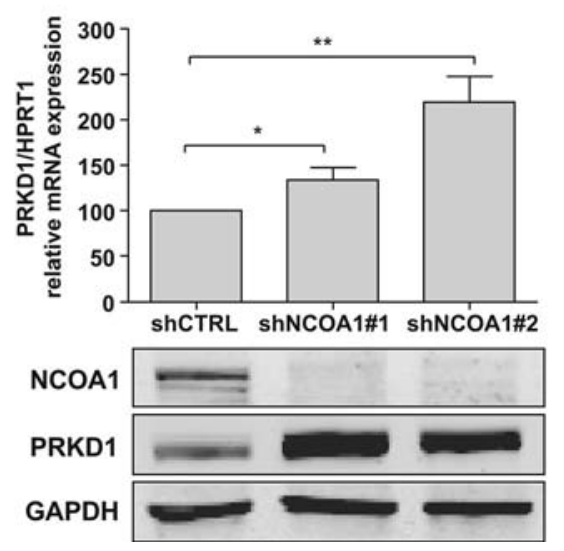

PC3

shNCOA1\#2 vs. ShCTRL

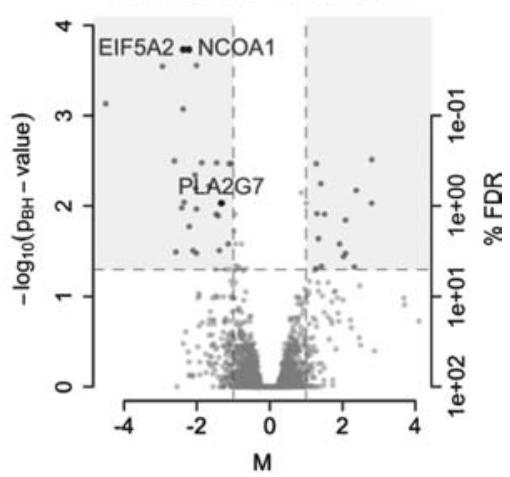

PC3

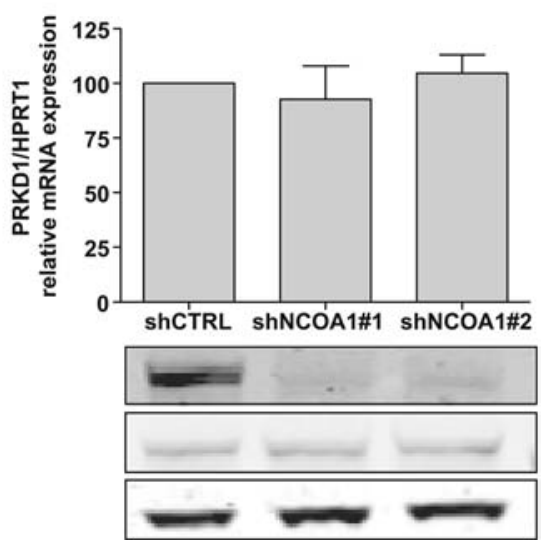

Figure 3

Impact of NCOA1 knockdown on the gene expression profile in NCOA1-depleted MDA PCa $2 b$ and PC3 cells. (A) mRNA of MDA PCa $2 b$ ShNCOA1\#2 and ShCTRL as well as PC3 ShNCOA1\#2 and ShCTRL cells was isolated, reverse transcribed and hybridized to a GeneChip Human Gene 1.0 ST Array (Affymetrix). Data was collected from three independent biological replicates. Volcano plot representing the differential gene expression upon NCOA1 knockdown in MDA PCa 2b (left panel) and PC3 (right panel) cells. Dashed lines indicate $M$ value (X-axis) as well as $\mathrm{p}_{\mathrm{BH}}$-value (Y-axis) cut-offs. (B) NCOA1 negatively regulates PRKD1 expression in AR-positive but not in AR-negative cell lines. PRKD1 mRNA level as well as protein expression was determined by qRT-PCR and Western blot, respectively. Data represent mean \pm S.E.M. from three independent experiments $(* P<0.05$; $* * P<0.01 ; t$-test). One representative Western blot is shown for both cell lines. 
in particular in the shNCOA1\#1 subline (Fig. 2A left panel). In PC3 cells, NCOA1 depletion significantly attenuated cellular motility in both NCOA1 knockdown sublines (Fig. 2A, right panel). To account for the previously shown differences in proliferation rates (Fig. 1B and C), counts of migrated cells were normalized to total cell number.

To test whether reduced migratory capacity upon NCOA1 knockdown may also result in reduced invasion, Boyden chambers coated with matrigel were used. In MDA PCa 2b cells, the effect of NCOA1 knockdown reduced invasiveness by approx. 40\% (Fig. 2B, left panel), while in PC3 cells, a significantly decreased invasion by $50 \%$ was detectable (Fig. 2B, right panel). Taken together, these results indicate that NCOA1 plays an important role in the migratory and invasive behavior of PCa cells independently of the AR expression status.

\section{Impact of NCOA1 knockdown on gene expression profile in MDA PCa $2 b$ and PC3 cells}

To identify a possible mechanism leading to decreased migration in MDA PCa $2 \mathrm{~b}$ and PC3 cells after NCOA1 knockdown, we performed a cDNA microarray using the
shCTRL and shNCOA1\#2 sublines, respectively. As shown in Fig. 3A, NCOA1 knockdown has a more pronounced effect in MDA PCa 2b cells with 433 up- and downregulated genes and a minor impact on AR-negative PC3 cells in which 41 genes were regulated (Supplementary Tables 1 and 2). Only one gene, namely POF1B (premature ovarian failure, 1B), was commonly regulated in both MDA PCa 2b and PC3 cells.

Additionally, we performed Gene Ontology (GO) analysis to identify regulated genes, which are involved in cellular motility (Supplementary Fig. 3). To verify the accuracy of the microarray results, mRNA expression of selected targets was analyzed by qRT-PCR in both NCOA1 depleted cell lines, shNCOA1\#1 and shNCOA1\#2 (Supplementary Fig. 4C). Within the MDA PCa $2 \mathrm{~b}$ set, we identified PRKD1 as a promising candidate, which was found earlier to be involved in the regulation of migration in other types of cancer (Jaggi et al. 2005, Sundram et al. 2011) by modifying proteins involved in actin remodeling (Sundram et al. 2014) and was furthermore listed in significantly enriched biological processes (BP) (Supplementary Fig. 3, highlighted by black arrows). Up-regulation of PRKD1 mRNA and protein upon
A

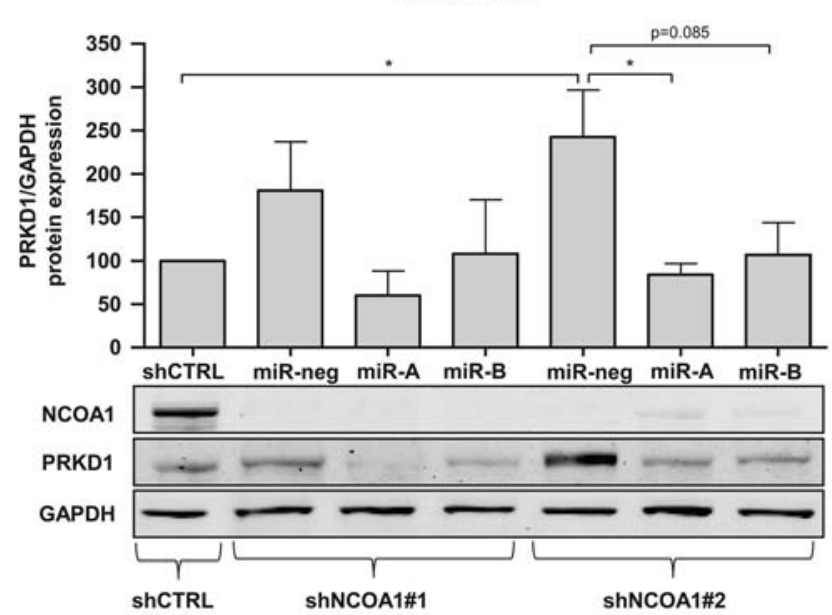

B MDA PCa 2b ShNCOA1\#1

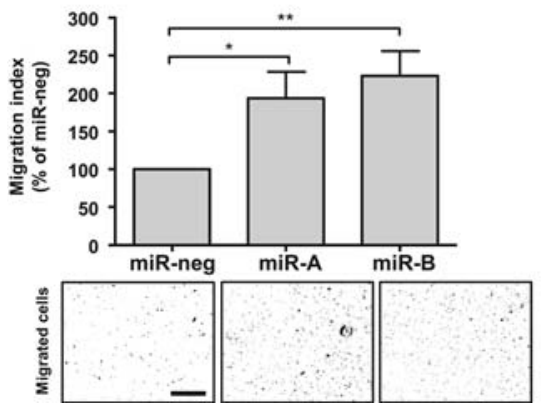

MDA PCa 2b shNCOA1\#2

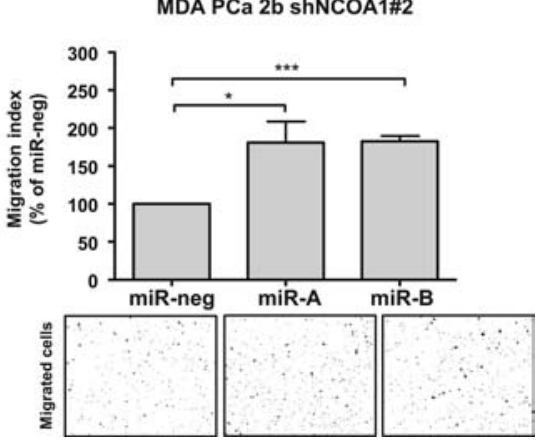

Figure 4

PRKD1 is involved in the migration of NCOA1depleted MDA PCa $2 b$ cells. (A) Western blot experiments showing protein levels of PRKD1 in MDA PCa $2 b$ shNCOA1\#1 and shNCOA1\#2 cells after stable transfection with two different microRNA sequences against PRKD1 (miR_A and miR_B, respectively) compared with miRnegative control. One representative Western blot out of three independent experiments is shown. Densitometric analysis was done on all experiments. PRKD1 expression in MDA PCa 2b shCTRL cells was set to $100 \%$. (B) Migration assays of stably infected MDA PCa $2 \mathrm{~b}$ shNCOA1\#1 and shNCOA1\#2 following PRKD1 knockdown. Equal numbers of cells were seeded in Boyden chambers with FluoroBlok cell culture inserts in duplicates. After $48 \mathrm{~h}$, the cells were stained with Calcein-AM and pictures of migrated cells were taken and quantified with ImageJ. Percentage of migrated cells was normalized to cells seeded without FluoroBlok cell culture inserts. Data show mean \pm s.E.M., $n \geq 4$ $\left({ }^{*} P<0.05 ; * * P<0.01 ; * * * P<0.001, t\right.$-test). Scale bar: $500 \mu \mathrm{m}$. 
NCOA1 down-regulation was verified in qRT-PCR and Western blot experiments (Fig. 3B, left panel). In PC3 cells, no regulation of PRKD1 was evident and basal PRKD1 expression was very low (Fig. 3B, right panel). From these results, we concluded that PRKD1 is differentially regulated in MDA PCa $2 \mathrm{~b}$ and PC3 cells upon NCOA1 knockdown. In conclusion, these results show that $N C O A 1$ is likely to regulate migration in AR-positive and -negative cells, but may implicate more than one single molecular mechanism.

\section{PRKD1 is a negative regulator of cell migration}

To further explore the functional role of PRKD1 as a possible suppressor of cell migration in MDA PCa $2 \mathrm{~b}$ cells, we established stable PRKD1 knockdown sublines using two different artificial miRNA targeting PRKD1 (miR-A and miR-B, respectively) in both NCOA1-depleted MDA PCa 2b sublines. Down-regulation of PRKD1 expression was verified on protein level (Fig. 4A). Boyden chamber assays were performed to clarify the functional role of PRKD1 in migration. Indeed, PRKD1 knockdown could significantly enhance the migratory potential of both MDA PCa 2b shNCOA1 sublines (Fig. 4B). These findings confirm our initial hypothesis that a molecular mechanism leading to the reduced migratory potential in MDA PCa 2b cells upon NCOA1 knockdown involves PRKD1.

\section{AR is a direct regulator of PRKD1 expression}

On the basis of previous results, we speculated that PRKD1 expression is regulated by the AR/NCOA1 complex. Hence, to uncover the role of AR in regulating PRKD1, we analyzed previously published ChIP-Sequencing data, which indeed revealed AR-binding sites mostly in the first intron of the PRKD1 gene in several cell lines as well as in patient samples. Moreover, a detailed investigation
A

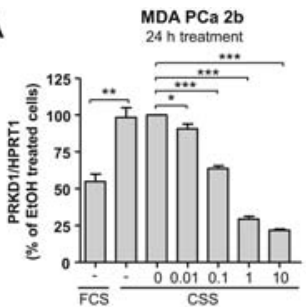

B

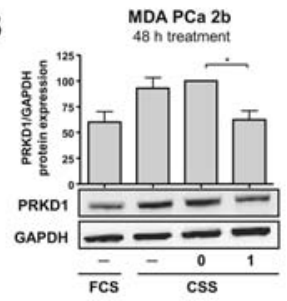

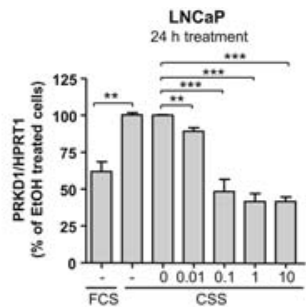

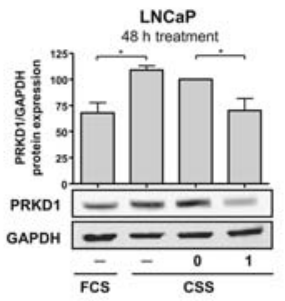

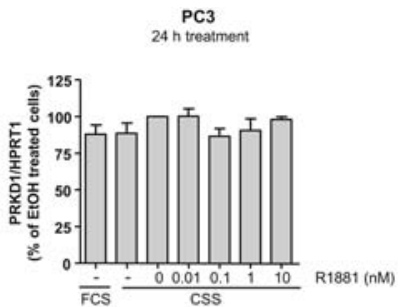

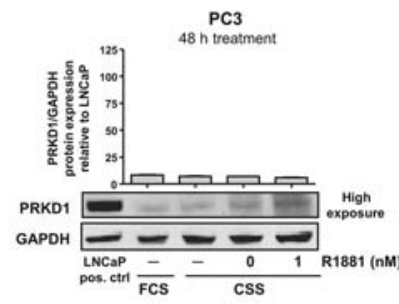

C
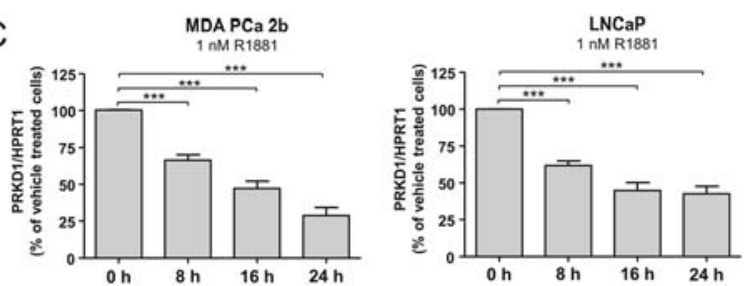

D
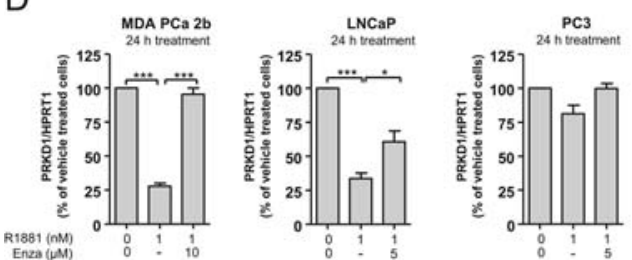

E

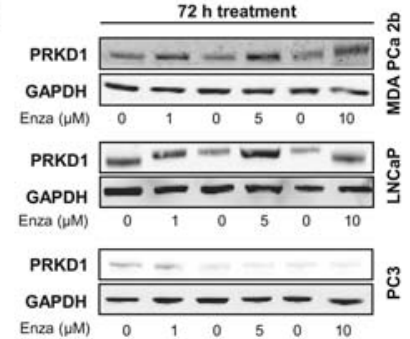

Figure 5

PRKD1 is negatively regulated by the AR. $(A, B)$ PRKD1 expression decreases in a concentrationdependent manner. Expression of PRKD1 was assessed by qRT-PCR (A) and Western blot with corresponding densitometric analysis (B), respectively, following steroid-deprivation using medium supplemented with $10 \%$ (for LNCaP and PC3) and 20\% (for MDA PCa 2b) charcoalstripped serum (CSS), respectively, for $24 \mathrm{~h}$. Cells were then treated with R1881 (0.01-10 nM) or left untreated (-) for additional $24 \mathrm{~h}$, as indicated. All values are normalized to $\mathrm{EtOH}$ vehicle control (0). Data represent mean of three independent experiments \pm S.E.M. ( ${ }^{*} P<0.05$; $* * P<0.01 ; * * * P<0.001$; $t$-test). (C) Time-course experiments. MDA PCa $2 \mathrm{~b}$ and LNCaP cells were treated with $1 \mathrm{nM}$ R1881 or EtOH vehicle control for the indicated time points following cultivation in CSS medium for $24 \mathrm{~h}$ and PRKD1 mRNA levels were measured by qRT-PCR. Values indicated are mean \pm S.E.M., $n=3$. (* $P<0.05$; $* * P<0.01 ; * * * P<0.001$; $t$-test). (D) The antiandrogen enzalutamide (Enza) treatment counteracted the effect of R1881. qRT-PCR data of MDA PCa 2b, LNCaP and PC3 cells treated with either vehicle control (0), $1 \mathrm{nM}$ R1881 or a combination of R1881 and enzalutamide for 24h. Data show mean \pm S.E.M., $n=4$. ( ${ }^{*} P<0.05$; $* * * P<0.001$; $t$-test). (E) MDA PCa $2 \mathrm{~b}, \mathrm{LNCaP}$ and $\mathrm{PC} 3$ cells were treated with increasing concentrations of enzalutamide or DMSO control (0) as indicated for $72 \mathrm{~h}$ and cell lysates were analyzed for PRKD1 expression by Western blot experiments. One representative Western blot out of three independent experiments is shown. 
of AR-binding sites identified in the LNCaP-AR dataset revealed that most of these sites are predicted to contain ARE motifs. (Stelloo et al. 2015, Bu et al. 2016) (Supplementary Fig. 5). Moreover, treatment with the synthetic androgen R1881 increased AR binding on the PRKD1 gene in the majority of AR-binding sites, whereas addition of enzalutamide abolished this effect (Supplementary Fig. 5; Detail view LNCaP-AR). To assess a PRKD1 regulation by the AR signaling axis, we treated steroid-starved MDA PCa 2b, LNCaP and PC3 cells with increasing concentrations of R1881. MDA PCa 2b and LNCaP cells showed a dose-dependent decrease in PRKD1 mRNA (Fig. 5A) and protein expression upon stimulation with 1 nM R1881 (Fig. 5B), whereas AR-negative cells were not affected. Furthermore, androgen withdrawal (CSS) promoted increased PRKD1 expression when compared with normal cell culture conditions (FCS).

To further analyze whether PRKD1 expression is directly regulated by the $\mathrm{AR}$, we performed a time-course experiment upon stimulation with $1 \mathrm{nM}$ R1881 in MDA PCa $2 \mathrm{~b}$ and LNCaP cells. A decreased expression of PRKD1 was detectable after $8 \mathrm{~h}$ compared with vehicle treated cells, further suggesting that the $\mathrm{AR}$ is a direct regulator of the PRKD1 gene (Fig. 5C).

Next, we asked whether enzalutamide, a clinically approved second-generation antiandrogen, may influence PRKD1 expression. Indeed, enzalutamide treatment was able to counteract the R1881-mediated down-regulation of PRKD1 in MDA PCa 2b and LNCaP, whereas PC3 cells were as expected unaffected (Fig. 5D). Similarly, enzalutamide,
A
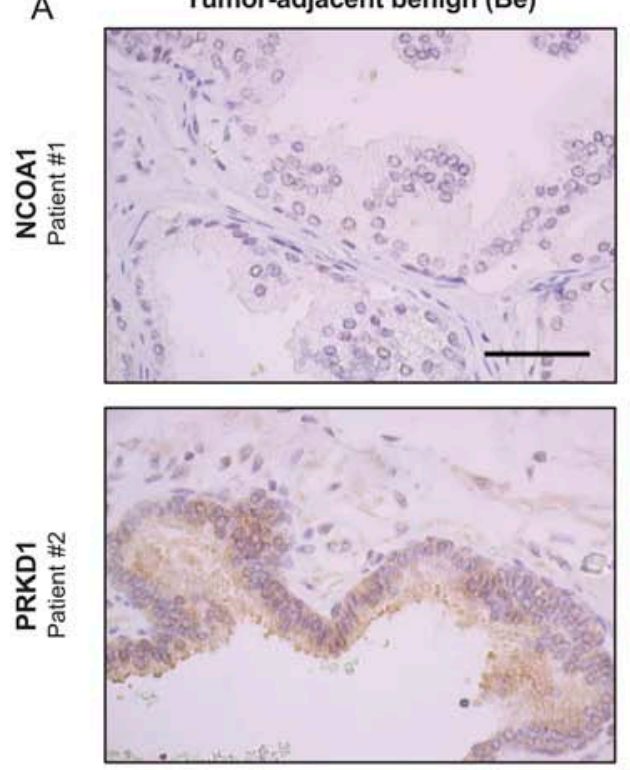
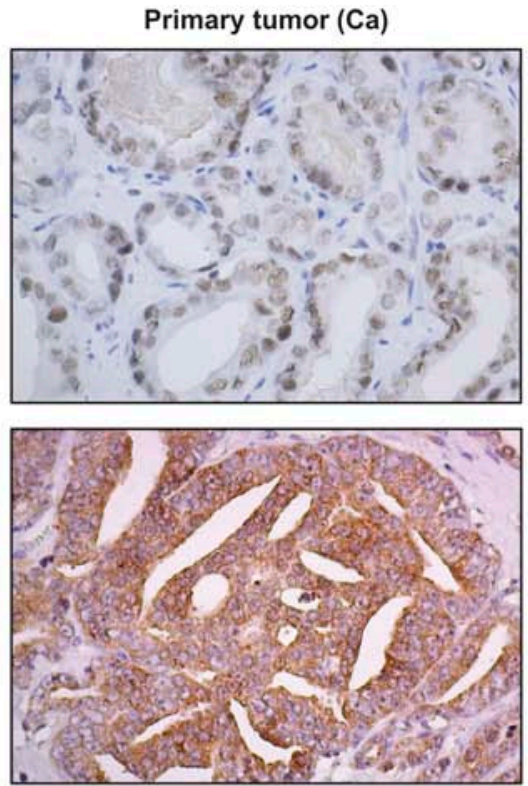
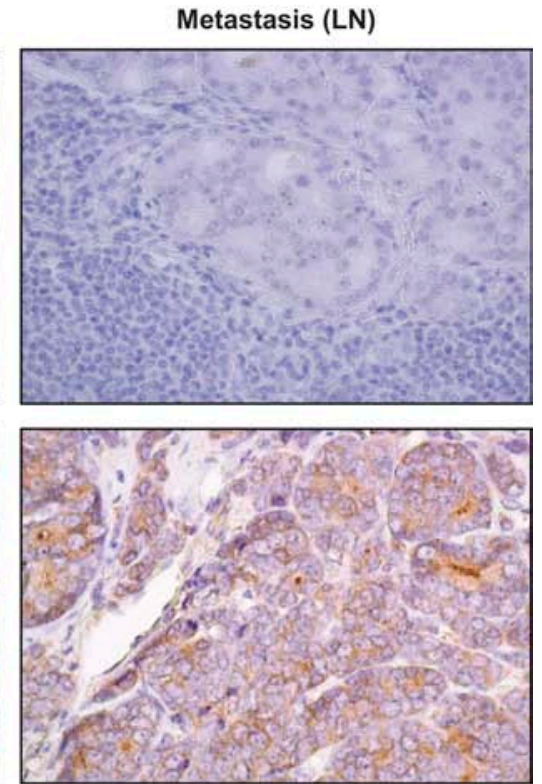

B

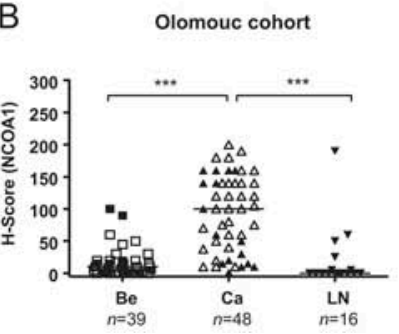

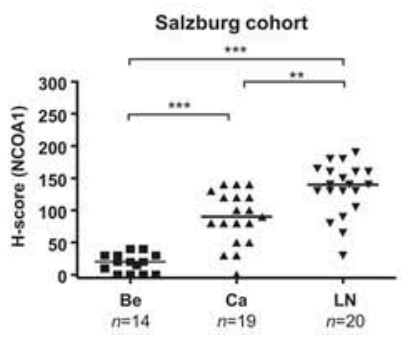

C
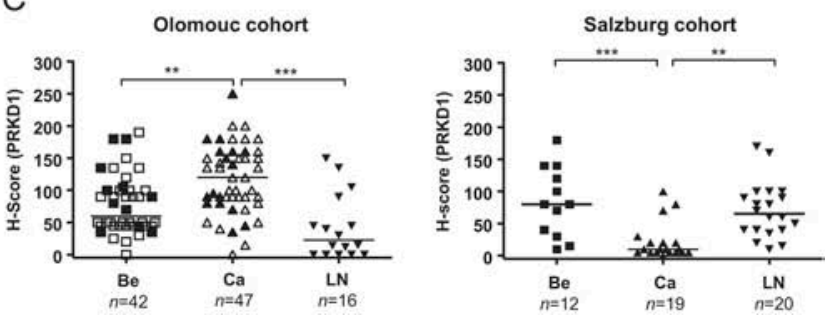

Figure 6

Analysis of NCOA1 and PRKD1 expression in human prostate tissue. (A) Representative images from tumor-adjacent benign tissue (Be), primary tumor (Ca) and lymph node metastasis (LN) samples of two patients are shown for NCOA1 (upper panel) and PRKD1 (lower panel) expression, as indicated. Scale bar represents $50 \mu \mathrm{m}$. (B) Evaluation of nuclear NCOA1 protein expression levels in luminal cells in tumor-adjacent benign, cancerous prostate tissue and lymph node metastasis from the Olomouc cohort (left panel) and the Salzburg cohort (right panel). Line indicates median. Filled symbols represent matched patients' samples (i.e. when Be, Ca and LN tissue from the same patient was available and evaluable). Empty symbols show unmatched samples. One-way ANOVA was used to determine significance (**P<0.01; *** $P<0.001$ ). (C) Evaluation of cytoplasmic PRKD1 expression in luminal cells of consecutive slices of the same specimens as in (B).

http://erc.endocrinology-journals.org DOI: 10.1530/ERC-16-0160
() 2016 Society for Endocrinology Printed in Great Britain
Published by Bioscientifica Ltd 
at concentrations between 1 and $10 \mu \mathrm{M}$, was able to increase PRKD1 protein expression after treatment for $72 \mathrm{~h}$ (Fig. 5E). Thus, PRKD1 is a gene negatively regulated by the AR and the AR/NCOA1 signaling axis directly down-regulates PRKD1 thereby affecting cellular migrative capacity.

\section{NCOA1 and PRKD1 protein expression in human prostate cancer samples}

In order to evaluate the expression of NCOA1 and PRKD1 in PCa patients, we performed immunohistochemistry (IHC) in two cohorts which included tumor-adjacent benign tissue, primary tumor samples and lymph node metastases (Fig. 6A). Antibody specificity was tested with appropriate formalin-fixed, paraffin-embedded (FFPE)-cell lines (Supplementary Fig. 7A). A higher NCOA1 expression was found in malignant areas compared with adjacent benign tissue in both cohorts. In the Olomouc cohort, NCOA1 staining decreased in lymph node sections, which might be explained by a very low expression of the AR in these samples, which also shows a significant positive correlation with NCOA1 staining (Supplementary Fig. 7C, $\mathrm{D}$ and E). However, in the Salzburg cohort, an opposite trend was observed (Fig. 6B). Differences between the two cohorts were observed also with regard to PRKD1 expression. Decreased PRKD1 expression was noted in lymph nodes in the Olomouc cohort, whereas lower PRKD1 expression was detected in primary tumors, but not in lymph node metastases in the Salzburg cohort (Fig. 6C). To verify the PRKD1 staining, we used an additional PRKD1 antibody (PRKD1_hpa) and repeated the IHC staining with the Olomouc cohort which revealed similar results (Supplementary Fig. 7B). Thus, we can show that NCOA1 is increasingly expressed in cancerous tissues compared with adjacent benign areas. With regard to the PRKD1 expression in the two cohorts, no definitive conclusion can be drawn and further analysis in bigger cohorts is warranted.

\section{Discussion}

Although novel therapies, i.e. inhibitors of androgen signaling and antiandrogens, have been introduced for castration-resistant PCa patients, responses are very heterogeneous and their impact on overall survival is limited. In order to further refine therapy, novel targets should be considered and mechanisms involved in cancer progression analyzed. In this study, we primarily aimed to test the effect of AR coactivator NCOA1 knockdown on migration and invasion as well as on regulation of target genes.

\section{NCOA1 regulates various cell migration pathways}

The ability of cells to migrate is an important step to spread to other organs. We demonstrated that one of the molecular mechanisms leading to decreased migratory capacity upon NCOA1 knockdown is mediated by PRKD1. According to literature, PRKD1 was found to negatively regulate proliferation and cell migration in various tumors, such as breast cancer (Eiseler et al. 2009) and PCa (Biswas et al. 2010, Du et al. 2010). Moreover, Jaggi and coworkers could show that PRKD1 overexpression in prostate cancer cells leads to decreased cellular motility (Jaggi et al. 2005). In addition, in colon cancer, PRKD1 overexpression negatively influenced motility partly by inhibiting the activity of cofilin (Sundram et al. 2014). However, PRKD1 was not regulated by NCOA1 in the AR-negative PC3, a cell line known to have high migratory and invasive capability (Santer et al. 2011). The low expression of PRKD1 in PC3 compared with AR-positive cell lines may be the explanation for its high motility. Epigenetic silencing of the PRKD1 promoter in PC3 cells could be a reason for the low expression, which was also shown for highly invasive breast cancer cell lines (Borges et al. 2013). An inhibitory effect of PRKD1 on cellular proliferation could be explained by stimulation of secretion of matrix metalloproteinases-2 and -9 (Biswas et al. 2010).

As a second point of interest, we aimed to explain the impaired migration of PC3 cells upon NCOA1 knockdown. On the basis of our cDNA microarray results as well as of GO analysis, we found two potential target genes which are known to affect migration, namely phospholipase A2 group7 (PLA2G7) (Vainio et al. 2011) and eukaryotic translation initiation factor 5A2 (EIF5A2) (Tang et al. 2010) (Table 1 ). We could verify the microarray data by qRT-PCR in both NCOA1-depleted PC3 cell lines. This could be a reasonable explanation for the reduced migration observed in PC3 cells (Supplementary Fig. 6). In conclusion, these results show that $N C O A 1$ is likely to regulate migration independently of the AR. Vainio and coworkers (2011) already demonstrated a prominent role of PLA2G7 in stimulation of PCa cell migration. Moreover, it has been shown that overexpression of EIF5A2 promotes metastasis in hepatocellular carcinoma (Tang et al. 2010). Collectively, our data show that NCOA1 is implicated in the modulation of migration and invasion in PCa. During the preparation of this manuscript, Crespi and coworkers (2015) have identified POF1B as a regulator of cell adhesion in human intestinal and keratinocyte cell lines. Hence, this protein, which was significantly up-regulated in MDA PCa $2 \mathrm{~b}$ and PC3 cells upon NCOA1 knockdown, may be one of the

Published by Bioscientifica Ltd 
Table 1 NCOA1-regulated genes in MDA PCa 2b and PC3 prostate cancer cells. Selected up- and down-regulated genes. Positive $\log _{2}$ FC values indicate higher expression in shNCOA1\#2 compared with shCTRL cells and negative $\log _{2}$ FC indicate lower expression.

\begin{tabular}{lcc}
\hline & \multicolumn{2}{c}{ MDA PCa 2b shNCOA1\#2 } \\
\cline { 1 - 1 } \cline { 3 - 3 } Gene of interest & Log $_{2} \mathrm{FCd}$ & $\mathrm{p}_{\mathrm{BH}}{ }^{\mathrm{e}}$ \\
PRKD1 & 1,82236661 & 0,000120547 \\
PLA2G7b & $-0,663331765$ & 0,084017798 \\
EIF5A2 $^{\mathrm{c}}$ & $-0,258584515$ & 0,566174804 \\
\hline
\end{tabular}

\begin{tabular}{cc}
\hline \multicolumn{2}{c}{ PC3 shNCOA1\#2 } \\
\hline Log $_{2}$ FC & $\mathrm{p}_{\mathrm{BH}}$ \\
$-0,079473852$ & 0,999710617 \\
$-1,326013737$ & 0,009357448 \\
$-2,370356648$ & 0,000184688
\end{tabular}

aProtein Kinase D1; bphospholipase A2, group 7; ceukaryotic translation initiation factor $5 \mathrm{~A} 2$; $\mathrm{d}^{\mathrm{d}} \log _{2}$ fold change; eadjusted $P$-value according to Benjamini and Hochberg.

proteins regulating migration in PCa cells as well and might be worth to be analyzed in more detail in the future.

\section{Differential AR/NCOA1-regulated gene expression}

On the basis of our results showing an increase in PRKD1 levels after down-regulation of NCOA1, we hypothesized that AR might be a direct regulator of PRKD1. Indeed, ChIP-Seq data set analysis revealed AR binding in several cell lines and patients samples. Moreover, the majority of AR-binding sites showed an increase in AR binding upon activation with R1881 that could be abolished by the addition of enzalutamide. Thus, AR acts as a repressor on the PRKD1 promoter. While AR is usually known to be an activator of gene expression, it may also negatively regulate transcription. For instance, the embryonic stem cell regulator Sox 2 and the regulatory subunit of the phosphatidylinositol 3-kinase R1 are repressed by androgenic hormones (Kregel et al. 2013, Munkley et al. 2015).

We have also assessed the role of NCOA1 in regulation of selected AR downstream target genes. PSA expression showed a decline in mRNA and protein level after NCOA1 depletion in LNCaP cells which is in line with results from Agoulnik and coworkers (2005). Another known direct target of the AR is FKBP5, which did not show an altered expression in mRNA or protein level in NCOA1-depleted LNCaP cells, which might be explained by the fact that another coactivator instead of NCOA1 is recruited by the AR for this target gene. On the other hand, in MDA PCa $2 b$ cells, PSA mRNA and secreted levels were not altered upon NCOA1 knockdown, although we could see an increase in intracellular protein level. MDA PCa $2 \mathrm{~b}$ cells already have an approximately 250 -fold higher secreted PSA level compared with LAPC4 cells cultured under normal conditions (Denmeade et al. 2003). This suggests that PSA expression might be deregulated in this castration-resistant cell line. One reason for the increase in intracellular PSA upon NCOA1 knockdown could be a deregulation in the secretory pathway. Therefore, we conclude that AR target genes are differentially regulated in androgen-dependent LNCaP and castration-resistant MDA PCa 2b cell lines.

\section{NCOA1 as a potential therapeutic target}

We found that NCOA1 knockdown leads to decreased proliferation in AR-positive cell lines. This confirms findings from Agoulnik and coworkers (2005) who showed decreased proliferation after a transient NCOA1 knockdown in the castration-resistant LNCaP derivative C4-2, while AR-negative PC3 and Du145 were unaffected. This corroborates NCOA1 as a potential therapeutic target for $\mathrm{PCa}$ as an alternative approach after ADT failure. On the basis of those and our results, we conclude that androgen-sensitive prostate cancer cells may be more efficiently targeted compared with cells that do not express AR. Santer and coworkers (2011) have already shown that knocking down another prominent coactivator, p300, decreases proliferation not only in androgen-sensitive LNCaP but also in androgen-insensitive PC3 cells. Taken together, this and previous publications (Agoulnik et al. 2005) show that cellular functions are affected in a larger number of models after knockdown of p300 compared with knockdown of NCOA1. However, development of specific experimental drugs could provide a definitive answer if there is a benefit by inhibiting both coactivators. For NCOA1, a small molecule inhibitor, gossypol, is available but has its limitations. It was reported that gossypol decreases not only NCOA1 but also NCOA3 protein levels (Wang et al. 2011), and that it may also work as an inhibitor of the antiapoptotic proteins $\mathrm{Bcl} 2 / \mathrm{BclXL}$ (Meng et al. 2008). Furthermore, it causes serious side effects (Coutinho 2002), and the majority of double-knockout $\mathrm{NCOA}^{-/-} / \mathrm{NCOA}^{-/-}$mouse embryos died by embryonic day 13.5 (Chen et al. 2010). Thus, targeting both coactivators simultaneously may not

Published by Bioscientifica Ltd 
necessarily provide therapeutic benefit. Additionally, NCOA1 has an important role in promoting metastasis, which was shown in genetically engineered breast cancer mouse models by Wang and coworkers (2009). Moreover, it was found that the disruption of the NCOA1 gene in mice resulted in a partial hormone resistance $\mathrm{Xu}$ 1998) and that an increased NCOA1 level is significantly associated with recurrence in aromatase inhibitor (AI)-treated breast cancer patients (McBryan et al. 2012).

In an attempt to develop novel NCOA1 targeting drugs, Nakka and coworkers (2013) established a new approach by inhibiting the p160 coactivator interface in the aminoterminal end of the AR with specifically designed peptides, which mimic the glutamine-rich region of the p160 coactivators. However, those peptides could not diminish cell growth of AR-negative cell lines and are not specific for NCOA1-AR interaction. Thus, more research work needs to be done to demonstrate the usefulness of NCOA1 targeted therapy to suppress tumor growth or, as demonstrated here, processes that regulate formation of metastases.

In terms of therapeutic targeting NCOA1, one should keep in mind that carboxy-terminal-truncated AR proteins that occur as a result of aberrant splicing are frequently found in patients who experienced ADT failure and developed a castration-resistant state (Mostaghel $\&$ Plymate 2011). These constitutively active AR, such as the AR-V7 that is expressed, e.g. in VCaP cells, are devoid of carboxy-terminal LBD. In such a case, it seems justified to target an AR coactivator such as NCOA1 that interacts particularly with the amino-terminus of the AR. Moreover, also in patients with AR mutations in the LBD, gained during the transition from androgen-dependent to castration-resistant stage, NCOA1 would be a reasonable target due to the fact that it binds to the amino-terminus of the $\mathrm{AR}$ and, therefore, the binding/coactivation is independent of mutations in the LBD. However, modulation of NCOA1 expression may have implications on glucocorticoid receptor (GR) activity since GR can be activated by AR inactivation to drive expression of AR-responsive genes (Arora et al. 2013). Further studies may answer the question whether knockdown of NCOA1 is compensated by other GR regulatory proteins.

\section{Variability in NCOA1 and PRKD1 expression in patients' specimens}

Finally, we have examined the expression of NCOA1 and PRKD1 in tumor-adjacent benign, primary and metastatic lymph node samples of PCa patients. Although we were able to include a limited number of lymph node metastases
(16 and 20 cases per cohort, respectively) obtained during radical prostatectomy in the immunohistochemical analysis, a definitive conclusion in terms of the tumorsuppressive role of PRKD1 could not be drawn at this stage. We may only speculate on the reasons of these contradictory findings between the two cohorts, but can exclude the following biases: all samples were obtained during radical prostatectomy of treatment-naïve patients. Nonspecific staining of the PRKD1 antibody can be ruled out, because two validated PRKD1 antibodies from two companies were used leading to similar results. Additionally, the antibody specificity was controlled on adequate FFPE cell lines. Stainings with the NCOA1 antibody confirm previous results of Agoulnik and coworkers showing higher NCOA1 levels in malignant areas compared with the matched benign tissue (Agoulnik et al. 2005). While Agoulnik and coworkers could show an increased NCOA1 expression in metastatic tissue samples, we detected a decreased NCOA1 expression in lymph node samples in the Olomouc cohort which may be explained by low AR expression in consecutive sections of the samples. However, in the Salzburg cohort, NCOA1 expression was up-regulated in metastatic patient material compared with cancerous areas which is in line with published data by Agoulnik and coworkers. The decline in expression of PRKD1 was observed only in primary tumors in the Salzburg cohort. It is worthwhile to mention that Du and coworkers (2010) compared PRKD1 microarray data between two patients' populations and noted statistically significant decrease only in one of those groups. More definitive conclusions may be drawn on larger, multicenter patient cohorts with specimens from treatment-naïve patients and patients undergoing or resistant to endocrine therapy. Unfortunately, access to these latter samples is quite limited. In consideration of heterogeneity of human $\mathrm{PCa}$, we propose that a subset of patients might benefit from anti-NCOA1 therapies and identification of these patients will require optimization of diagnostic laboratory procedures.

In summary, we demonstrate for the first time that the AR/NCOA1 complex stimulates migration of $\mathrm{PCa}$ cells through suppression of PRKD1. Mechanistically, our in vitro data extend the knowledge on NCOA1 as a therapy target and PRKD1 as a suppressor of processes leading to metastasis formation.

\section{Supplementary data}

This is linked to the online version of the paper at http://dx.doi.org/10.1530/ ERC-16-0160.

Published by Bioscientifica Ltd 


\section{Declaration of interest}

The authors declare that there is no conflict of interest that could be perceived as prejudicing the impartiality of the research reported.

\section{Funding}

This work was supported by the Austrian Science Fund FWF (Grant No. W1101-B12) (to Z C), Czech Ministry of Education (Grant No. NPU I LO1304) and Czech Ministry of Health (Grant No. NV 15-28628A (to G K and J B)).

\section{Acknowledgements}

We thank Irma Sottsas for doing the specificity testing of NCOA1 antibody with FFPE cell lines. We are also grateful to Gertrud Feiersinger, MSc, for preparing FFPE cell lines for PRKD1 (Santa Cruz) antibody testing and to Mag. Eberhard Steiner for his support in statistical analysis. The authors are grateful to Prof. Walther Parson for authentication of cell lines and Prof. Reinhard Kofler for helpful suggestions. We thank all members of the Division of Experimental Urology for helpful discussions.

\section{References}

Agoulnik IU, Vaid A, Bingman WE, Erdeme H, Frolov A, Smith CL, Ayala G, Ittmann MM \& Weigel NL 2005 Role of SRC-1 in the promotion of prostate cancer cell growth and tumor progression. Cancer Research 65 7959-7967. (doi:10.1158/0008-5472. CAN-04-3541)

Arora VK, Schenkein E, Murali R, Subudhi SK, Wongvipat J, Balbas MD, Shah N, Cai L, Efstathiou E, Logothetis C, et al. 2013 Glucocorticoid receptor confers resistance to antiandrogens by bypassing androgen receptor blockade. Cell 155 1309-1322. (doi:10.1016/j. cell.2013.11.012)

Benjamini Y \& Hochberg Y 1995 Controlling the false discovery rate: a practical and powerful approach to multiple testing on JSTOR. Journal of the Royal Statistical Society, Series B 57 289-300.

Bindreither D, Ecker S, Gschirr B, Kofler A, Kofler R \& Rainer J 2014 The synthetic glucocorticoids prednisolone and dexamethasone regulate the same genes in acute lymphoblastic leukemia cells. BMC Genomics 15 662. (doi:10.1186/1471-2164-15-662)

Biswas MHU, Du C, Zhang C, Straubhaar J, Languino LR \& Balaji KC 2010 Protein kinase D1 inhibits cell proliferation through matrix metalloproteinase-2 and matrix metalloproteinase-9 secretion in prostate cancer. Cancer Research 70 2095-2104. (doi:10.1158/00085472.CAN-09-4155)

Borges S, Döppler H, Perez EA, Andorfer CA, Sun Z, Anastasiadis PZ, Thompson EA, Geiger XJ \& Storz P 2013 Pharmacologic reversion of epigenetic silencing of the PRKD1 promoter blocks breast tumor cell invasion and metastasis. Breast Cancer Research 15 R66. (doi:10.1186/ bcr3460)

Bu H, Narisu N, Schlick B, Rainer J, Manke T, Schäfer G, Pasqualini L, Chines P, Schweiger MR, Fuchsberger C, et al. 2016 Putative prostate cancer risk SNP in an androgen receptor-binding site of the melanophilin gene illustrates enrichment of risk snps in androgen receptor target sites. Human Mutation 37 52-64. (doi:10.1002/ humu.22909)

Chen X, Liu Z \& Xu J 2010 The cooperative function of nuclear receptor coactivator 1 (NCOA1) and NCOA3 in placental development and embryo survival. Molecular Endocrinology 24 1917-1934. (doi:10.1210/me.2010-0201)

Coutinho EM 2002 Gossypol: a contraceptive for men. Contraception 65 259-263. (doi:10.1016/S0010-7824(02)00294-9)
Craft N, Shostak Y, Carey M \& Sawyers CL 1999 A mechanism for hormone-independent prostate cancer through modulation of androgen receptor signaling by the HER-2/neu tyrosine kinase. Nature Medicine 5 280-285. (doi:10.1038/6495)

Crespi A, Bertoni A, Ferrari I, Padovano V, Della Mina P, Berti E, Villa A \& Pietrini G 2015 POF1B localizes to desmosomes and regulates cell adhesion in human intestinal and keratinocyte cell lines. Journal of Investigative Dermatology 135 192-201. (doi:10.1038/ jid.2014.327)

Culig Z \& Santer FR 2014 Androgen receptor signaling in prostate cancer. Cancer Metastasis Reviews 33 413-427. (doi:10.1007/s10555013-9474-0)

Culig Z, Hoffmann J, Erdel M, Eder IE, Hobisch A, Hittmair A, Bartsch G, Utermann G, Schneider MR, Parczyk K, et al. 1999 Switch from antagonist to agonist of the androgen receptor bicalutamide is associated with prostate tumour progression in a new model system. British Journal of Cancer 81 242-251. (doi:10.1038/sj.bjc.6690684)

Denmeade SR, Sokoll LJ, Dalrymple S, Rosen DM, Gady AM, Bruzek D, Ricklis RM \& Isaacs JT 2003 Dissociation between androgen responsiveness for malignant growth vs. expression of prostate specific differentiation markers PSA, hK2, and PSMA in human prostate cancer models. Prostate 54 249-257. (doi:10.1002/ pros.10199)

Du C, Zhang C, Hassan S, Biswas MHU \& Balaji KC 2010 Protein kinase D1 suppresses epithelial-to-mesenchymal transition through phosphorylation of snail. Cancer Research 70 7810-7819. (doi:10.1158/0008-5472.CAN-09-4481)

Eiseler T, Döppler H, Yan IK, Goodison S \& Storz P 2009 Protein kinase D1 regulates matrix metalloproteinase expression and inhibits breast cancer cell invasion. Breast Cancer Research 11 R13. (doi:10.1186/ bcr2232)

Erb HHH, Langlechner RV, Moser PL, Handle F, Casneuf T, Verstraeten K, Schlick B, Schäfer G, Hall B, Sasser K, et al. 2013 IL6 sensitizes prostate cancer to the antiproliferative effect of IFN $\alpha 2$ through IRF9. Endocrine-Related Cancer 20 677-689. (doi:10.1530/ERC-13-0222)

Hobisch A, Ramoner R, Fuchs D, Godoy-Tundidor S, Bartsch G, Klocker H \& Culig Z 2001 Prostate cancer cells (LNCaP) generated after long-term interleukin 6 (IL-6) treatment express IL-6 and acquire an IL-6 partially resistant phenotype. Clinical Cancer Research 7 2941-2948.

Hoefer J, Schfer G, Klocker H, Erb HHH, Mills IG, Hengst L, Puhr M \& Culig Z 2012 PIAS1 is increased in human prostate cancer and enhances proliferation through inhibition of p21. American Journal of Pathology 180 2097-2107. (doi:10.1016/j.ajpath.2012.01.026)

Jaggi M, Rao PS, Smith DJ, Wheelock MJ, Johnson KR, Hemstreet GP \& Balaji KC 2005 E-cadherin phosphorylation by protein kinase $\mathrm{D} 1 /$ protein kinase $\mathrm{C}\{\mathrm{mu}\}$ is associated with altered cellular aggregation and motility in prostate cancer. Cancer Research 65 483-492.

Karantanos T, Corn PG \& Thompson TC 2013 Prostate cancer progression after androgen deprivation therapy: mechanisms of castrate resistance and novel therapeutic approaches. Oncogene 32 5501-5511. (doi:10.1038/onc.2013.206)

Kregel S, Kiriluk KJ, Rosen AM, Cai Y, Reyes EE, Otto KB, Tom W, Paner GP, Szmulewitz RZ \& Vander Griend DJ 2013 Sox2 is an androgen receptor-repressed gene that promotes castration-resistant prostate cancer. PLOS ONE $\mathbf{8}$ e53701. (doi:10.1371/journal. pone.0053701)

Malinowska K, Neuwirt H, Cavarretta IT, Bektic J, Steiner H, Dietrich H, Moser PL, Fuchs D, Hobisch A \& Culig Z 2009 Interleukin-6 stimulation of growth of prostate cancer in vitro and in vivo through activation of the androgen receptor. Endocrine-Related Cancer 16 155-169. (doi:10.1677/ERC-08-0174)

Mathelier A, Fornes O, Arenillas DJ, Chen C-Y, Denay G, Lee J, Shi W, Shyr C, Tan G, Worsley-Hunt R, et al. 2015 JASPAR 2016: a major expansion and update of the open-access database of transcription
(C) 2016 Society for Endocrinology Printed in Great Britain
Published by Bioscientifica Ltd 
factor binding profiles. Nucleic Acids Research 44 D110-D115. (doi:10.1093/nar/gkv1176)

McBryan J, Theissen SM, Byrne C, Hughes E, Cocchiglia S, Sande S, O'Hara J, Tibbitts P, Hill ADK \& Young LS 2012 Metastatic progression with resistance to aromatase inhibitors is driven by the steroid receptor coactivator SRC-1. Cancer Research 72 548-559. (doi:10.1158/0008-5472.CAN-11-2073)

Meng Y, Tang W, Dai Y, Wu X, Liu M, Ji Q, Ji M, Pienta K, Lawrence T \& Xu L 2008 Natural BH3 mimetic (-)-gossypol chemosensitizes human prostate cancer via Bcl-xL inhibition accompanied by increase of Puma and Noxa. Molecular Cancer Therapeutics 7 2192-2202. (doi:10.1158/1535-7163.MCT-08-0333)

Mostaghel EA \& Plymate S 2011 New hormonal therapies for castrationresistant prostate cancer. Endocrinology and Metabolism Clinics of North America 40 625-642. (doi:10.1016/j.ecl.2011.05.013)

Munkley J, Livermore KE, McClurg UL, Kalna G, Knight B, McCullagh P, McGrath J, Crundwell M, Leung HY, Robson CN, et al. 2015 The PI3K regulatory subunit gene PIK3R1 is under direct control of androgens and repressed in prostate cancer cells. Oncoscience 2 755-764.

Nakka M, Agoulnik IU \& Weigel NL 2013 Targeted disruption of the p160 coactivator interface of androgen receptor (AR) selectively inhibits AR activity in both androgen-dependent and castration-resistant AR-expressing prostate cancer cells. International Journal of Biochemistry \& Cell Biology 45 763-772. (doi:10.1016/j.biocel.2012.12.012)

Parson W, Kirchebner R, Mühlmann R, Renner K, Kofler A, Schmidt S \& Kofler R 2005 Cancer cell line identification by short tandem repeat profiling: power and limitations. FASEB Journal 19 434-436. (doi:10.1096/fj.04-3062fje)

Pasqualini L, Bu H, Puhr M, Narisu N, Rainer J, Schlick B, Schäfer G, Angelova M, Trajanoski Z, Börno ST, et al. 2015 miR-22 and miR-29a are members of the androgen receptor cistrome modulating LAMC1 and Mcl-1 in prostate cancer. Molecular Endocrinology 29 1037-1054. (doi:10.1210/me.2014-1358)

Powell SM, Christiaens V, Voulgaraki D, Waxman J, Claessens F \& Bevan CL 2004 Mechanisms of androgen receptor signalling via steroid receptor coactivator-1 in prostate. Endocrine-Related Cancer 11 117-130. (doi:10.1677/erc.0.0110117)

Qin L, Liu Z, Chen H \& Xu J 2009 The steroid receptor coactivator-1 regulates twist expression and promotes breast cancer metastasis. Cancer Research 69 3819-3827. (doi:10.1158/ 0008-5472.CAN-08-4389)

Santer FR, Höschele PPS, Oh SJ, Erb HHH, Bouchal J, Cavarretta IT, Parson W, Meyers DJ, Cole PA \& Culig Z 2011 Inhibition of the acetyltransferases p300 and CBP reveals a targetable function for p300 in the survival and invasion pathways of prostate cancer cell lines. Molecular Cancer Therapeutics 10 1644-1655. (doi:10.1158/1535-7163.MCT-11-0182)

Slabáková E, Kharaishvili G, Smějová M, Pernicová Z, Suchánková T, Remšík J, Lerch S, Straková N, Bouchal J, Král M, et al. 2015 Opposite regulation of MDM2 and MDMX expression in acquisition of mesenchymal phenotype in benign and cancer cells. Oncotarget 6 36156-36171. (doi:10.18632/oncotarget.5392)

Smyth GK 2004 Linear models and empirical bayes methods for assessing differential expression in microarray experiments. Statistical Applications in Genetics and Molecular Biology 3 Article 3. (doi:10.2202/1544-6115.1027)

Stelloo S, Nevedomskaya E, van der Poel HG, de Jong J, van Leenders GJ, Jenster G, Wessels LF, Bergman AM \& Zwart W 2015 Androgen receptor profiling predicts prostate cancer outcome. EMBO Molecular Medicine 7 1450-1464. (doi:10.15252/ emmm.201505424)

Sundram V, Chauhan SC \& Jaggi M 2011 Emerging roles of protein kinase D1 in cancer. Molecular Cancer Research 9 985-996. (doi:10.1158/1541-7786.MCR-10-0365)

Sundram V, Ganju A, Hughes JE, Khan S, Chauhan SC \& Jaggi M 2014 Protein kinase D1 attenuates tumorigenesis in colon cancer by modulating $\beta$-catenin/T cell factor activity. Oncotarget 5 6867-6884. (doi:10.18632/oncotarget)

Tang D-J, Dong S-S, Ma N-F, Xie D, Chen L, Fu L, Lau SH, Li Y, Li Y \& Guan X-Y 2010 Overexpression of eukaryotic initiation factor 5A2 enhances cell motility and promotes tumor metastasis in hepatocellular carcinoma. Hepatology 51 1255-1263. (doi:10.1002/hep.23451)

Vainio P, Lehtinen L, Mirtti T, Hilvo M, Seppänen-Laakso T, Virtanen J, Sankila A, Nordling S, Lundin J, Rannikko A, et al. 2011 Phospholipase PLA2G7, associated with aggressive prostate cancer, promotes prostate cancer cell migration and invasion and is inhibited by statins. Oncotarget 2 1176-1190. (doi:10.18632/ oncotarget)

Wang S, Yuan Y, Liao L, Kuang S-Q, Tien JC-Y, O’Malley BW \& Xu J 2009 Disruption of the SRC-1 gene in mice suppresses breast cancer metastasis without affecting primary tumor formation. PNAS 106 151-156. (doi:10.1073/pnas.0808703105)

Wang Y, Lonard DM, Yu Y, Chow D-C, Palzkill TG \& O'Malley BW 2011 Small molecule inhibition of the steroid receptor coactivators, SRC-3 and SRC-1. Molecular Endocrinology 25 2041-2053. (doi:10.1210/ me.2011-1222)

Xu J 1998 Partial hormone resistance in mice with disruption of the steroid receptor coactivator-1 (SRC-1) gene. Science 279 1922-1925. (doi:10.1126/science.279.5358.1922)

Received in final form 30 May 2016

Accepted 2 June 2016

Accepted Preprint published online 2 June 2016
() 2016 Society for Endocrinology Printed in Great Britain
Published by Bioscientifica Ltd. 